\title{
Clay buildings in modern energy efficient construction
}

\author{
Adham Giyasov ${ }^{1, *}$, Unusjon Barotov ${ }^{2}$, Firdavs Naimov $^{1}$ \\ ${ }^{1}$ Moscow State University of Civil Engineering, Yaroslavskoe shosse, 26, Moscow, 129337, Russia \\ ${ }^{2}$ Tajik Technical University named after Academician M.S. Osimi Radzhabov avenue, 10, 734000, \\ Republic of Tajikistan
}

\begin{abstract}
The best practices of using low-tech traditional materials are summarized, and the role of clay in modern architectural design and construction is revealed. The cost of energy for the construction of buildings with the use of ecological clay technology is much lower than with the use of industrial building construction technologies. Thermophysical and bioclimatic studies have allowed determining the thermal properties of walls made of clay, clay materials and their role in the formation of a comfortable microclimate of the premises. When examining the carrying capacity of the structural system of buildings, vulnerable buildings were identified, on the basis of which research and development constructive methods for strengthening clay walls were developed and proposed for use in the practice of designing and building buildings. They ensure high reliability and comfort of living of people in the standard and special climatic conditions of the territories. The developed methods of strengthening the structural parts and the technology of construction made of clay with high reliability will expand the construction in normal and special climatic conditions of the territories.
\end{abstract}

\section{Introduction}

The purpose of the study is based on the study of the history and technology of construction of buildings made of Adobe walls in different climatic conditions, identifying the advantages and vulnerabilities of parts of buildings made of clay and the development of design solutions. Clay lepianka is the oldest method of building walls. You can also lay the walls of unburned brick, you can make blocks of clay mixed with straw, heather or even cane. You can also build the walls of the house, filling the clay formwork, the so-called Adobe. You can also make tiles from clay mixed with the cement.

In Yemen, the city of Shibam is built entirely of dry clay. Built in the XIX and XX century buildings have a height of 10 floors. These houses are still in good condition.

Simplicity in production, availability of raw materials made raw the most mass wall material of the region of the East, and also the European countries [1-3].

Clay masonry was widespread in Central Asia and in the neighboring regions of the East as the main building material (Afghanistan, Iran, Iraq, the African continent). So,

\footnotetext{
*Corresponding author: adham52@mail.ru
} 
from" pahsa " i.e. a clay laying, Palace buildings, country dwellings of settlements of the East were erected $[4,5]$.

Simplicity in production, existence of raw materials made raw the most mass wall material of Central Asia. Dwellings in Jericho still stand as a Testament to the longevity of earthen houses. Adobe and clay, as a building material, has been popular throughout Europe from the UK to the Kuban, wherever the soil has a high clay content. Thousands of old clay dwellings are still used as residences in the UK. And Adobe houses and clay huts now stand in the villages in all countries. Currently, more than 300 thousand apartments in Germany are built of clay. Most of the historic buildings in Europe, built of clay, are located in France (15\% of the buildings were built before 1900). In the Grenoble-LyonChacon region, most towns and small rural settlements are built of unburned clay (up to $80 \%$ of buildings). These are schools, mansions and factories. In the Grenoble appeared a clay village, houses and buildings for other purposes which are built of clay. "Pahsa" was a widespread material in Central Asia and neighboring countries. For example, in the earliest layers of Tepe Sialk near Kashia, erected on the ruins of the ancient agricultural settlements of Iran in the Neolithic can be traced the remains of clay walls $[6,7]$.

"Pahsa" fit thick, about a meter high, layers with division into blocks. Techniques such a brickwork perfectly illustrates Palace Kalai kahkaha the building, the lower part of the walls of which are indicative of smooth polished granite [6]. After laying, each row was cut from the side surfaces on the plumb. Due to this, the pahsa when drying cracks not in a random, but in a given direction. The overlying row is cut into a bandage with the first, so that the seams do not coincide, than monolithic and beautiful blocks are obtained. Indicative examples of this type of masonry are the walls of the first tier of the keshka AkTepe near Tashkent [8].

"Pahsa" requires clay of a certain quality - quite fat and viscous. If the clay does not have these qualities, it is used with a significant admixture of pebbles. The walls of ancient buildings in the mountainous areas of Turkestan and Zeravshan ranges are made of such composition. Data on raw materials are given in a number of works devoted to archeology and ancient architecture of Central Asia. Much attention is paid to the technology of production of raw bricks, methods of masonry from it, combining it with pakhsa, increasing their energy efficiency $[9,10]$. Wide use of the wood in construction was caused, in-the first, by its qualities (plasticity, small thermal conductivity, ease of processing), in-the second, the universal distribution making it the most available material. Non-burning building materials based on loess, such as clay masonry (pahsa), raw brick, architectural ornament, sculpture and clay dough - mortar, also play an important role in the construction of modern buildings. The total cost of energy for the construction of buildings using environmental technology clay plus wood is seven times lower than with the use of largepanel technologies of construction of buildings. Reducing housing costs is a real opportunity for the masses of poor people to build their own homes. The use of local construction material is also employment for the unemployed from the area, as well as hard - to-reach areas and areas with complex orography.

\section{The formulation and method of solving the optimization problem}

Adobe construction requires the same careful science-based approach as any other types of construction. Proof of this are numerous studies in this area, in recent years, based on popular methods of construction of buildings. Adobe construction is progressing not only in countries with weak economic potential, but also in economically developed countries. The use of this material has virtually no boundaries, if you use it with maximum benefit, eliminating the shortcomings. 
The widespread use of clay in modern construction of buildings and structures is dictated by the fact that the construction of a building made of clay material has a number of serious advantages such as: strength, durability, resistance and fire resistance; low cost and availability, a huge stock in all regions of the world; simplicity of construction and construction of the building; environmental friendliness; adaptability; low thermal conductivity and at the same time high accumulative ability to heat the building; permeability to solar energy, and at the same time protected from harmful solar radiation; applicability in all climatic zones of the globe.

At first glance, Adobe construction seems to be a complicated problem. However, the impatient acquaintance with it shows that the problem is easily solved if we collect and organize positive solutions in this area, bring them into the system and determine the ways of their scientific and practical improvement.

The works carried out in the field of construction of buildings, restoration of monuments of architecture, require knowledge of ancient building materials, structures and technology of their construction, as well as natural and climatic conditions in which the material was tested. To answer these questions, it is necessary to clarify what components and in what proportions it was made and in what theological way it was prepared.

Before the appearance of burnt brick (IX century) all buildings were built of raw brick.

The compositions of the raw bricks are different. For the purpose to prevent cracking of a brick in clay sand or Adobe generally were mixed. In structures VIII-X centuries the ancient settlement Krasnaya Rechka in the dough raw bricks added chopped straw (Adobe) or reeds, and sometimes wool. In the southern regions of Central Asia (ancient Bactria), sand, small river pebbles and pieces of ceramics were sometimes added to the brick.

In the construction machinery of the lower reaches of the Syr Darya and Amu Darya used square brick [14], and in the Central regions of Central Asia (Ustrushana, Samarkand, Sogd) - almost exclusively rectangular, with a ratio of 1:2.

The raw brick was not less ancient construction material which application in the Middle East began, at least, 10 thousand years ago and now they find the application in modern construction. Depending on the amount of foreign impurities clay is divided into fat, medium fat clay and sand. Fatty clays have no more than $10-15 \%$ of sandy impurities, average fat content - $16-25 \%$, sandy, as grafted, more than $25 \%$. In assessing the quality of clay can be limited to the establishment of the degree of fat content, plasticity and water resistance. The quality of clay can be determined by a simple inspection. Fatty clay does not crumble when rolling out a small ball with your fingers, it is easily formed, and when kneading, impurities are not felt. On a cut fat plastic clay has glossy Shine of a surface; at planning a knife does not crumble, and gives a thin shaving. When wet, it sticks to your hands. To set the quality of clay should be carried out some simplified experiments. Compare different samples of clay to determine its fat content, it is necessary with each class, which can be used by the developer for construction, roll small balls weighing up to $50 \mathrm{~g}$ and put them on the air to dry. On the surface of the balls of greasy clay will crack, and balls of lean clay will remain intact.

The plasticity of clay is easier to install so. A ball of clay should be put on the floor from a height of $1 \mathrm{~m}$. And if the low-plasticity clay, bead breaks or crumbles, if plastic, only flattened. Significantly affect the quality of walls of clay, especially Adobe, raw, genevalogic, the process of preparation of clay mass and, in particular, the degree of loosening. The best and cheapest way to prepare clay is to freeze it. For this purpose clay on a place develop in the fall. The extracted clay are imported to the construction site and placed in ridge height of 1 and a width of not more than $2.5 \mathrm{~m}$. the Length of the ridge could be anything, depending on needs. During the autumn rains the clay becomes saturated with water. During the winter, it repeatedly freezes and melts, resulting in a violation of its natural structure, as the clay swells. For better penetration of water in the ridge to the depth 
of the stakes to make holes. Keeping clay in the summer months makes sense only if it is often watered. For storage of moisture in clay it is necessary to cover it with wet matting. The height of the ridge should be no higher than $0.5 \mathrm{~m}$. In cases where exposure of the clay in the summer months is not possible, it should be artificially loosened and moistened with water for three days. Simultaneously with clay it is necessary to prepare fillers which reduce thermal conductivity of a clay wall. Various materials of mainly organic origin with a small volume weight (straw, cane, storm in the form of a section with a length of fibers of 3-4 cm) are used as fillers. Fillers of clay mass can also serve as sawdust, finely chopped straw, moss, etc. They should be used in dry form, while straw, cane, weed must be moistened with water before adding to the clay. The filler can be slag. The size of the largest particles of slag should not exceed $20 \mathrm{~mm}$. Mineral (coarse-grained sand, soft crushed stone) and fibrous organic fillers (straw, hay, seeding, pine needles, etc.) are used as fillers in clay. In this case, mineral additives, especially stony fillers should be completely dry.

A prerequisite for high quality construction of clay is impeccable preparation of clay, which must have a fine-grained structure, which is achieved by careful mixing.

We should pay particular attention that the designs of all Adobe buildings should be thoroughly isolated from the possible ingress of moisture. As a rule, moisture in walls can get from slanting rains, action of forces of capillarity, i.e. hit of moisture from the soil, and also badly executed isolation: malfunctions of a roof, internal condensation of the steam getting into walls, the splashes getting from a roof on the earth.

In the former Soviet Union, clay was used and is used in the construction of low-rise residential, public and even some industrial buildings, as well as almost all economic buildings, in all republics, especially where there are no other materials, or the construction of these buildings from another material is economically impractical or these materials must be saved for high-rise construction. One of the reasons for the widespread use of clay in the construction of buildings and structures, without conditionally, is the efficiency of construction of low-rise buildings, where the strength of the material is sufficient, and there is a fairly large amount of construction.

\section{Results}

The building with clay walls is much lighter in comparison with other materials due to the smaller volume weight of the clay-straw mass and by reducing (by 25-30\%) the thickness of the walls. The material of such walls has a lower thermal conductivity for thermal calculation of walls under stationary conditions of heat transfer in winter conditions and has sufficient inertial properties for effective damping of the amplitude of temperature fluctuations in summer extreme conditions of buildings, providing good thermal stability of the walls, especially in areas with hot climate in which, human thermal regime $\mathrm{FE}=100$ $\mathrm{g} / \mathrm{h}$ is within the limits of comfort mouth (table, fig. 1).

Full-scale measurements of the summer temperature conditions of the premises of the southern dwelling with Adobe and large-panel walls showed the following amplitudes of temperature fluctuations:

-air air at day $42{ }^{\circ} \mathrm{C}$, at night $25^{\circ} \mathrm{C}$;

-internal air housing with adobe walls with a coefficient of thermal conductivity of 0.80 $\mathrm{W} /\left(\mathrm{m}{ }^{\circ} \mathrm{C}\right)$ during the day $28.0{ }^{\circ} \mathrm{C}$, at night $26.5{ }^{\circ} \mathrm{C}$, moisture loss of a person by evaporation $\mathrm{FE}=100 \mathrm{~g} / \mathrm{h}$. Evaluated according to the norms as the comfort of the environment;

-internal air dwelling with large-panel walls with a coefficient of thermal conductivity of $0.58 \mathrm{~W} /\left(\mathrm{m}{ }^{\circ} \mathrm{C}\right)$ during the day $34{ }^{\circ} \mathrm{C}$, at night $31{ }^{\circ} \mathrm{C}$. It is assessed according to the norms as discomfort of the environment. 
There is a difference in air temperature between buildings with adobe and panel walls at $5.0 \ldots 5.5^{\circ} \mathrm{C}$.

Table 1. Heat engineering indicators of building materials and products.

\begin{tabular}{|c|c|c|c|c|c|c|c|}
\hline \multirow{3}{*}{$\begin{array}{l}\mathrm{N} \\
\mathrm{pp}\end{array}$} & \multirow{3}{*}{ Material } & \multirow{3}{*}{$\begin{array}{c}\text { Density } \\
\text { in dry } \\
\text { condition } \\
\rho, \\
\mathrm{kg} / \mathrm{m}^{3}\end{array}$} & \multicolumn{5}{|c|}{ Coefficients } \\
\hline & & & \multicolumn{2}{|c|}{$\begin{array}{c}\text { thermal } \\
\text { conductivity, } \\
\lambda, \\
\mathrm{W} /\left(\mathrm{m}^{\circ} \mathrm{C}\right)\end{array}$} & \multicolumn{2}{|c|}{$\begin{array}{l}\text { heat build-up (at } \\
\text { a period of } 24 \mathrm{~h}) \\
\mathrm{s}, \\
\mathrm{W} /\left(\mathrm{m}^{2}{ }^{\circ} \mathrm{C}\right)\end{array}$} & \multirow[t]{2}{*}{$\begin{array}{c}\text { vapor } \\
\text { permeability } \\
\mathrm{mg} /(\mathrm{m} \mathrm{h} \mathrm{Pa})\end{array}$} \\
\hline & & & A & Б & A & Б & \\
\hline 1 & $\begin{array}{l}\text { Clay and raw } \\
\text { walls }\end{array}$ & 2000 & 0,72 & 0,83 & 10,55 & 11,18 & 0,17 \\
\hline \multirow{3}{*}{2} & Laminated wall & 1600 & 0,58 & 0,70 & 9,2 & 9,75 & 0,14 \\
\hline & clay-sand & 1800 & 0,58 & 0,70 & 8,7 & 9,22 & 0,17 \\
\hline & clay-sawdust & 800 & 0,23 & 0,29 & 4,85 & 4,89 & 0,32 \\
\hline 3 & $\begin{array}{l}\text { Vegetable soil } \\
\text { under the } \\
\text { building }\end{array}$ & 1800 & 1,0 & 1,16 & 11,95 & 11,95 & - \\
\hline
\end{tabular}

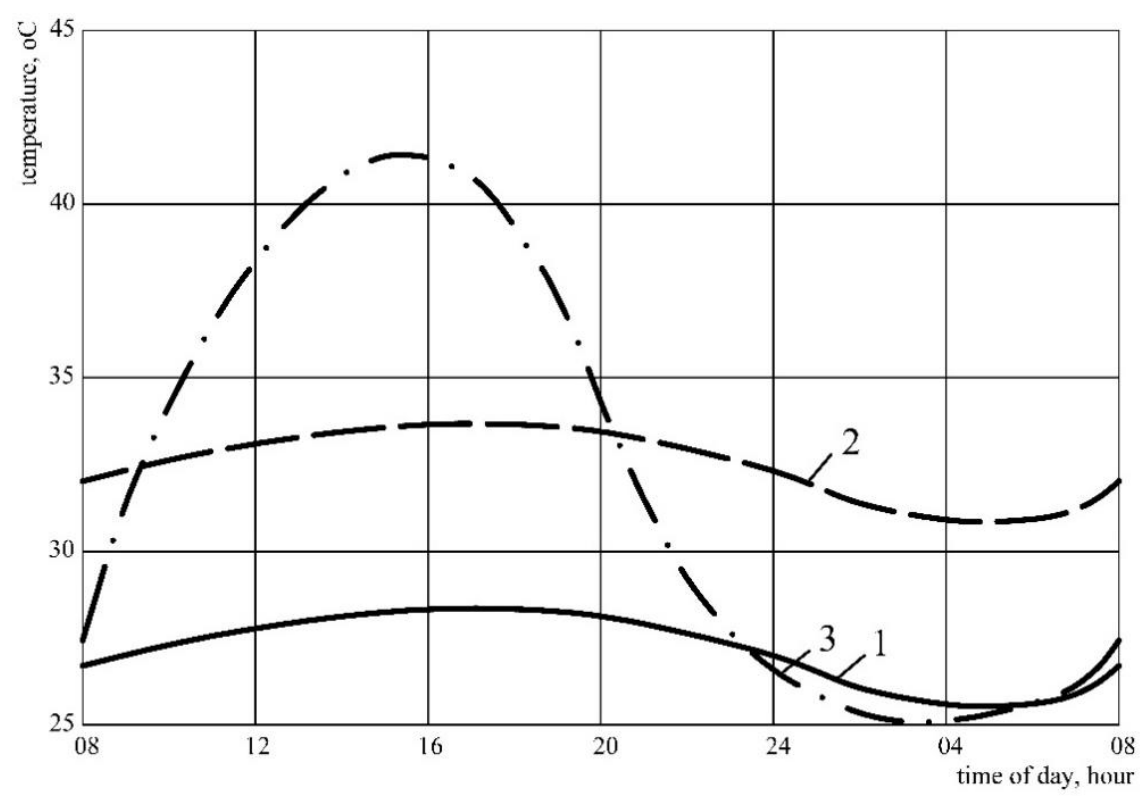

Fig. 1. Daily air temperature running, where: 1 -in a folk dwelling with mud walls, 2 -in a modern dwelling, 3-outside temperature.

Given the experience of the use of clay in the past of the Middle East can be recommended for modern construction in rural conditions of Adobe, clay, clay-straw construction, traditional manufacturing experience which has not lost its importance in the current environment.

The analysis shows that low-rise, individual construction of buildings in rural areas and even in cities is mainly based on clay (Adobe, clay, etc.) and stone. And in some areas of clay is built up to $80-85 \%$ of homes. From this material are constructed and in a mass order 
are under construction now and 2-3 floor residential buildings in rural areas and in the cities, public and, even, production buildings. This material is used in all climatic zones of the globe - and in hot and cold climates, as well as seismic areas covering large areas.

However, it is noted that houses built of clay in seismic countries have a number of serious drawbacks. Almost all of these houses are built by individual developers without a project and, accordingly, without calculating the effect of dynamic horizontal seismic effects. These houses are built on the basis of practical intuition of individual developers. Perhaps a small part of these buildings are resistant to all power effects. But, as the technology and methods of construction of these buildings, their resistance against the calculated seismic effects is extremely insufficient. If we consider that today more than a billion people live in houses made of soil material on the globe, the scale of a possible disaster from the destruction of these buildings becomes quite obvious.

During its long history, mankind has developed a number of techniques and principles for the construction of buildings and structures that can withstand the effects of various natural phenomena. These principles have been tested on real objects for centuries. Many of these objects were destroyed by earthquakes and other natural phenomena, some of them are well preserved to this day. Buildings without reinforcement, regardless of the method of construction, are not earthquake-resistant, and their construction and operation is of concern. Clay buildings with reinforced walls, depending on the method of strengthening, have different strengths and with such walls can be erected buildings that can resist natural phenomena of different forces.

By identifying vulnerable parts of the building developed scientifically based design solutions of clay walls, reinforced in various ways and proposed for use in the practice of design and construction, some of which are shown below in Fig. 2.
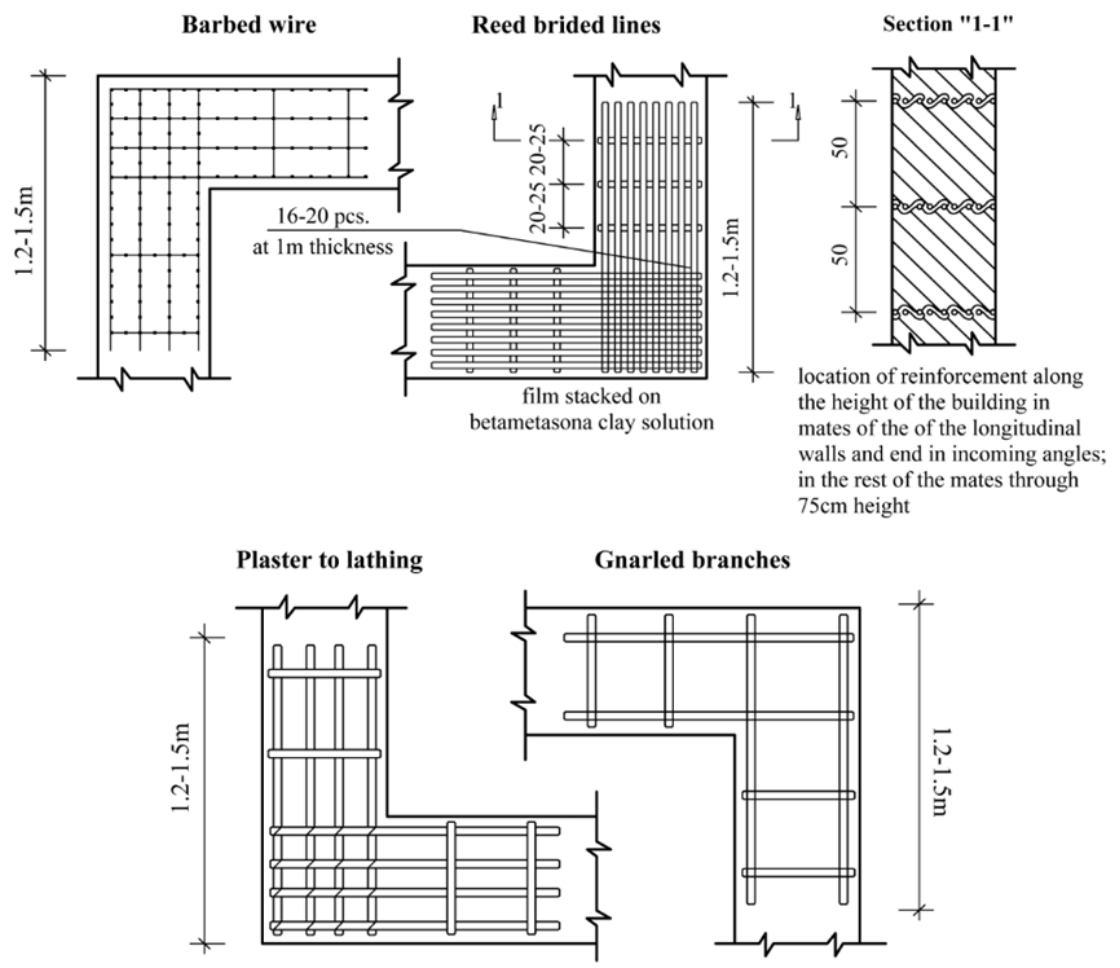

Fig. 2. Construction of walls reinforced in various ways. 
As a result, it is noted that in the development of the bioarchitectural environment, the design and construction of adobe buildings from natural material plays a very important role.

Thus, in conclusion, it is noted that traditional houses made of clay (clay-pahsa, mud brick) belong to "low-tech" trends in the construction industry, practicing the use of local natural environmental materials, and advocate for saving resources and developing traditional skills and solutions that From time to time they retained their relevance, especially in rural construction, as well as in the construction of buildings on complex mountainous terrain.

The study of the experience of building houses made of clay allowed us to identify positive and negative features. On the basis of identifying vulnerable parts of buildings, methods were developed for strengthening structural parts and the technology of building houses made of clay with high reliability in normal and special climatic conditions of the territories.

\section{Acknowledgements}

The work was carried out in accordance with the plan of the research work of the department on the problem "Construction, function and environment in the architecture of buildings and cities".

\section{References}

1. S.W. Baba, A.L. Zanna, M.M. Mustapha, International Journal of Sustainable Construction Engineering \& Technology 4(2), 39-46 (2013)

2. F.T. Merdassa, Problems of science 3(28), 73-77 (2018)

3. I. Khalil, S.M. Halabi, Z.S. Alhalabi, Bulletin of the peoples friendship University of Russia, Series: Engineering studies 1, 166-171 (2016)

4. E.D. Zilivinskaya, Essays on the cult and civil architecture of the Golden Horde (Astrakhan University, Astrakhan, 2011)

5. A. Gebeyehu, B. Marco, G. Behailu, Housing conditions and demand for housing in urban Ethiopia (Irp-Cnr, Roma, 2001)

6. S.M. Mamadzhanova, K.T. Usmanov, Construction culture of Northern Tajikistan XIX-XX Centuries (Meros, Dushanbe, 2002)

7. F.M. Chakaev, R.U. Chetaeva, V.V. Reutova, Fundamental research 12-6, 1191-1196 (2014)

8. T.S. Nurulin, Architecture and construction of Uzbekistan. Tashkent 1, 49-51 (2013)

9. T.Ya. Vavilova, E.M. Mantsurova, Bulletin of the school of engineering FEFU 2(27), 5

10. Y.A. Tabunshchikov, M.M. Brodach, N.V. Shilkin, Energy efficient buildings (AVOKPRESS, Moscow, 2003) 